\title{
OPTIMAL RESPONSE-RELATED WEIGHTING MATRICES TO CONTROL SEMI-ACTIVE BASE ISOLATION SYSTEMS
}

\author{
Hamed DADKHAH ${ }^{1 *}$, Mahsa NORUZVAND ${ }^{1}$
}

\section{Abstract}

In this paper, the performance of a semi-active base isolation system, including a magneto-rheological (MR) damper and base isolation system for different combinations of response-related weighting matrices, has been studied. To consider all possible sets of response-related matrices, seven H2/linear quadratic Gaussian (LQG) control designs have been considered. For a numerical simulation, a six-story shear frame has been subjected to different earthquakes, and the performance of the control system has been evaluated. The results show that the optimal force-related weighting parameter is identical for different sets of response-related weighting matrices and is also independent of earthquake records when minimizing the maximum base drift is considered as the design objective. Also, the results of different sets of response-related weighting matrices show that the optimal sets for the design objective of minimizing the maximum base drift are the velocity and displacement/velocity-related weighting matrices.

\section{Address}

1 Faculty of Engineering, Department of Civil Engineering, University of Mohaghegh Ardabili, Ardabil, Iran

* Corresponding author: h.dadkhah@uma.ac.ir

\section{Key words}

- Semi-active base isolation system,

- $\mathrm{H}_{2} /$ LQG control algorithm,

- Response-related weighting matrix,

- Force-related weighting parameter.

\section{INTRODUCTION}

Base isolation systems are known as an efficient control system to protect structures against earthquakes. By using this control system, the fundamental period of structures increases because of the low stiffness of base isolation systems in comparison with the structural stiffness, while the base drift is excessive as a result of this low degree of stiffness. When the maximum base drift is more than the desired value, the use of supplemental control systems is required. In previous research, various control systems have been studied in combination with base isolation systems, which can be classified into three groups: passive (Constantinou et al., 1999), semi-active (Narasimhan and Nagarajaiah, 2006), and active (Inaudi and Kelly, 1993; Nagarajaiah et al., 1993; Yang et al., 1996) control systems. Among these systems, semi-active control systems have been studied more than other control systems because they need a low external power supply to operate and can also be adapted to different conditions. Variable orifice damper systems (Madden et al., 2002; Wongprasert and Symans, 2005) and variable friction systems (Narasimhan and Nagarajaiah, 2006) are the semi-active control systems that have been studied as supplemental base isolation systems. The MR damper is another semi-active control system that has been widely investigated both separately (Dyke et al., 1996; Jing et al., 2004; Cho et al., 2005; Bharti et al., 2014) as well as in combination with a base isolation system (Yoshioka et al., 2002; Lee et al., 2006; Ali and Ramaswamy, 2009). Ramallo et al. (2002) showed that using an adjustable MR damper in the base can reduce the base drift of an isolated structure. Sahasrabudhe and Nagarajaiah (2005) demonstrated the effectiveness of using an MR damper in reducing the bearing displacement in bridges equipped with sliding base isolation systems. A semi-active base isolation system has also been employed to control the vibration of critical non-structural equipment. Fan et al. (2009) fixed a semi-active base isolation between equipment and a floor and experimentally showed the effectiveness of this control system in mitigating the vibration of the equipment. Jung et al. (2006) studied the effect of different semi-active control algorithms on the performance 
of the hybrid control system of an MR damper and base isolation and showed that when the design objective is to reduce base drift without regard to the floor acceleration, a clipped optimal control algorithm is recommended. In this research, due to considering the minimization of the maximum base drift as the design objective, this control algorithm is employed to control the MR damper behavior. To operate a clipped-optimal control algorithm, the desired control force should be determined for each time step. Shook et al. (2007) used a linear quadratic regulator (LQR) controller for determining the desired control force and controlling the semi-active base isolation. They showed that using an LQR/clipped optimal controller is superior to fuzzy logic control and a neural network control in most cases. Another controller used in most previous research as well as in this paper to calculate the desired control force is an $\mathrm{H}_{2}$ /linear quadratic Gaussian (LQG) controller (Johnson et al., 1998; Ramallo et al., 2002; Yoshioka et al., 2002). To determine the desired control force, the performance index is defined in $\mathrm{LQR}$ and $\mathrm{H}_{2} / \mathrm{LQG}$ controllers so that its design parameters are a response-related weighting matrix and a force-related weighting parameter. Mohebbi et al. (2015) determined a force-related weighting parameter optimally by using a genetic algorithm, while the response weighting matrix was related to the structural acceleration.

In most previous research, the response-related weighting matrices considered to control a semi-active base isolation system could be categorized into two groups. In the first group, a displacement/ acceleration-related weighting matrix has been employed (Johnson et al., 1998; Ramallo et al., 2002), while in the second group, the response weighting matrix was related to the displacement, velocity and acceleration of the structure (Yoshioka et al., 2002). Bahar et al. (2003) studied the effect of different response-related weighting matrices on the performance of active mass dampers, while their effect on the performance of a semi-active base isolation system has not been investigated. In this paper, the response of a structure controlled by a semi-active base isolation system is compared for various combinations of response weighting matrices related to displacement, velocity and acceleration to determine the optimal set to minimize the maximum base drift for which the MR dampers have been added to the base isolation system.

\section{SEMI-ACTIVE BASE ISOLATION SYSTEM}

Previous research (Johnson et al., 1998; Yoshioka et al., 2002; Mohebbi et al., 2015), demonstrated that the structural behavior controlled by a semi-active base isolation system is located in the linear region. Therefore, the equation of the motion of the structure controlled by this system can be written as:

$$
M_{s} \ddot{x}+C_{s} \dot{x}+K_{s} x=\Gamma f-M_{s} \Lambda \ddot{x}_{g}
$$

where $\Gamma=\left[\begin{array}{ll}-1 & 0_{i \times 1}\end{array}\right]^{T}$ indicates the location of an MR damper that has been fixed between the ground and base isolation system; $\Lambda$ and $f$ are respectively a unit vector and the MR damper force; $\ddot{x}_{g}$ is the ground acceleration; $x$ is the structure displacement vector relative to the ground; and $M_{s}, K_{s}$ and $C_{s}$ are respectively the mass, stiffness and damping matrices of the system. In this paper, a linear elastomeric with low damping is considered as the base isolation system because it is employed in combination with an MR damper, and the utilization of a high damping base isolation system is not needed. In the dynamic model of structures controlled by base isolation systems, one degree of freedom is added to the dynamic model of the structure so that its dynamic parameters depend on the characteristics of the base isolation system.

The state-space form of the equation of motion is given by:

$$
\dot{Z}=A Z+B f+E \ddot{x}_{g}
$$

$$
y=C Z+D f+v
$$

where $Z$ is the state vector $\left(Z=[x, \dot{x}]^{T}\right) ; v$ is the measurement noise vector; $y$ is the vector of measured outputs, which in this paper is defined as a vector including the acceleration, displacement and velocity of the structure (i.e. $[\ddot{x}, x, \dot{x}]$ ); and $A, B, C, D$ and $E$ are system matrices that for a structural system with an $\mathrm{n}$-degree of freedom can be written as:

$$
\begin{gathered}
A=\left[\begin{array}{cc}
0_{n \times n} & I_{n \times n} \\
-M_{s}^{-1} K_{s} & -M_{s}^{-1} C_{s}
\end{array}\right], B=\left[\begin{array}{c}
0_{n \times 1} \\
M_{s}^{-1} \Gamma
\end{array}\right], E=\left[\begin{array}{c}
0_{n \times 1} \\
\Lambda_{n \times 1}
\end{array}\right], \\
C=\left[\begin{array}{cc}
-M_{s}^{-1} K_{s} & -M_{s}^{-1} C_{s} \\
I_{n \times n} & 0_{n \times n} \\
0_{n \times n} & I_{n \times n}
\end{array}\right], D=\left[\begin{array}{c}
M_{s}^{-1} \Gamma \\
0_{n \times 1} \\
0_{n \times 1}
\end{array}\right],
\end{gathered}
$$

In this paper, the MR damper has been modeled by the modified Bouc-Wen model. The mechanical model of the MR damper is shown in Figure 1 (Dyke et al., 1996).

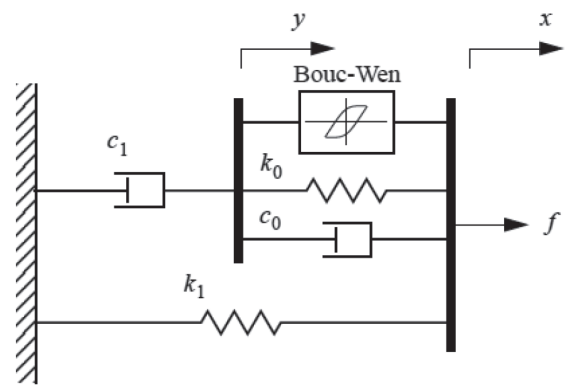

Fig. 1 Modified Bouc-Wen model of the MR damper

The force predicted by this model is given as (Dyke et al., 1996):

$$
f=a z+c_{0}(\dot{x}-\dot{y})+k_{0}(x-y)+k_{1}\left(x-x_{0}\right)
$$

or equivalently

$$
\begin{gathered}
f=c_{1} \dot{y}+k_{1}\left(x-x_{0}\right) \\
\dot{z}=-\gamma|\dot{x}-\dot{y}| z|z|^{n-1}-\beta(\dot{x}-\dot{y})|z|^{n}+A(\dot{x}-\dot{y}) \\
\dot{y}=\frac{1}{c_{1}+c_{0}}\left\{a z+c_{0} \dot{x}+k_{0}(x-y)\right\}
\end{gathered}
$$

where $x$ and $x_{0}$ are the displacement and the initial displacement of the damper; $y$ and $z$ are respectively the internal displacement of the MR damper and the evolutionary variable; $k_{l}, c_{0}$ and $c_{1}$ represent the accumulator's stiffness, viscous damping and dashpot, respectively; $k_{0}$ is present to control the stiffness during large velocities; and the parameters $\gamma, \beta$ and $A$ are used to define the shape of the hysteresis loops.

The MR damper's behavior depends on the value of the voltage current. Spencer et al. (1997) proposed the following equations to determine the dynamic parameters of an MR damper based on the applied voltage:

$$
\begin{gathered}
a=a(u)=a_{a}+a_{b} u \\
c_{1}=c_{1}(u)=c_{1 a}+c_{1 b} u \\
c_{0}=c_{0}(u)=c_{0 a}+c_{0 b} u
\end{gathered}
$$

where $u$ is given as the output of a first-order filter as given by: 


$$
\dot{u}=-\eta(u-V)
$$

$V$ and $\eta$ are respectively the value of the voltage and the constant modulus.

\section{CONTROL ALGORITHM}

Dyke et al. (1996) employed a clipped-optimal control algorithm to control an MR damper. In this paper, the MR damper voltage is applied using the following algorithm:

$$
V=V_{\max } H\left\{\left(f_{c}-f\right) f\right\}
$$

$V_{\max }$ is the maximum voltage that can be applied to an MR damper, and $H\{$.$\} is the Heaviside step function. It is clear that the ap-$ plied voltage is set to zero or that the maximum voltage is based on the properties of the Heaviside step function. A block diagram of the clipped-optimal control is shown in Figure 2. The desired control force $f$ is determined by the $\mathrm{H}_{2} / \mathrm{LQG}$ control algorithm that has been used in most previous research (Johnson et al., 1998; Ramallo et al., 2002; Yoshioka et al., 2002). A block diagram of the semi-active control system is presented in Figure 3. In the $\mathrm{H}_{2} / \mathrm{LQG}$ algorithm, $\ddot{x}_{g}$ is taken to be a stationary white noise, and the structural responses are minimized by the use of the following performance index:

$$
J=\lim _{\tau \rightarrow \infty} \frac{1}{\tau}\left[\int_{0}^{\tau}\left(y^{T}(t) Q y(t)+r f_{c}^{2}\right) d t\right]
$$

where $Q$ and $r$ are the response weighting matrix and force weighting parameter. The response weighting matrices are defined as:

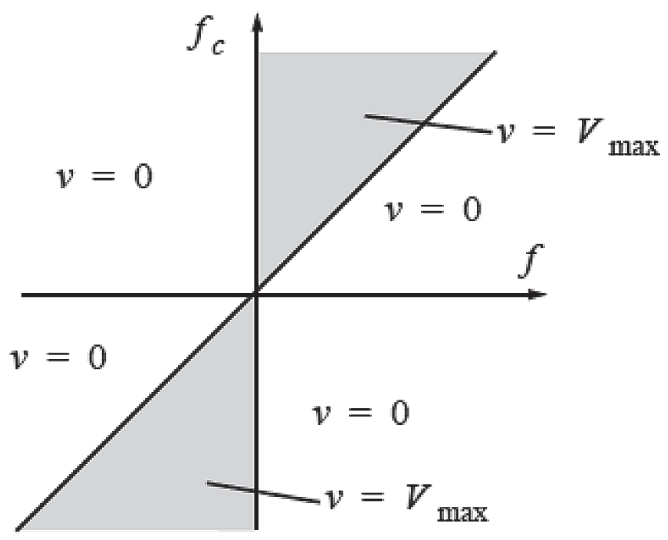

Fig. 2 Block diagram of a clipped-optimal control algorithm

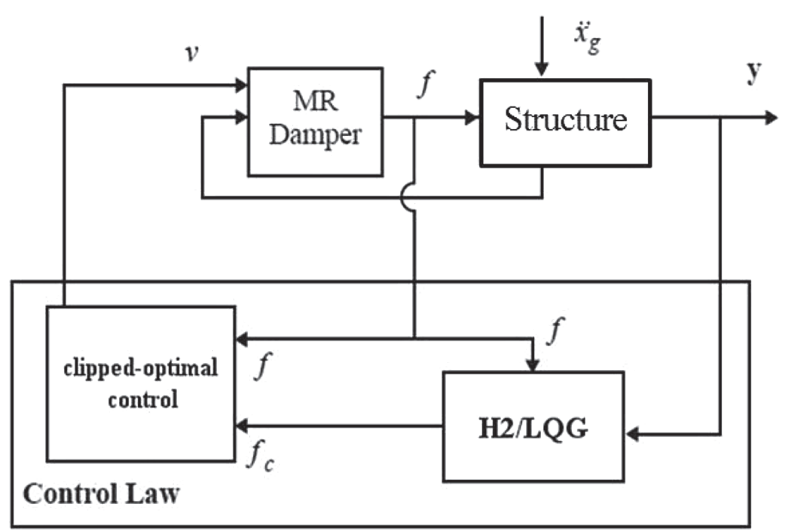

Fig. 3 Block diagram of a semi-active control system

$$
Q=\left[\begin{array}{ccc}
q_{a} I_{n \times n} & 0_{n \times n} & 0_{n \times n} \\
0_{n \times n} & q_{d} I_{n \times n} & 0_{n \times n} \\
0_{n \times n} & 0_{n \times n} & q_{v} I_{n \times n}
\end{array}\right]
$$

The various combinations of acceleration, displacement and velocity-related weighting matrices are considered with the definition of $q_{d}, q_{d}$ and $q_{v}$ as equal to 0 or 1 . In this paper, the response weighting matrix is defined as constant, and the force weighting parameter is determined optimally.

The desired control force is determined by minimizing the performance indexes as follows:

$$
\begin{gathered}
f_{c}=-k_{c} \bar{z} \\
\overline{\dot{z}}=\overline{A z}+B f+L(y-C \bar{z}-D f)
\end{gathered}
$$

$k_{c}$ is the gain matrix for LQR; and $L$ is the gain matrix for the state estimator, which is determined as:

$$
\begin{aligned}
& k_{c}=\frac{B^{\prime} P}{r} \\
& L=(C S)^{\prime}
\end{aligned}
$$

where $P$ and $S$ is determined by solving the algebraic Ricatti equation.

\section{NUMERICAL EXAMPLE}

For a numerical analysis, a six-story shear building has been considered; the dynamic parameters of the structure are taken as $m_{1}=$ $m_{2}=\ldots=m_{6}=345.6$ tons, $k_{1}=k_{2}=\ldots=k_{6}=340.4 \mathrm{MN} / \mathrm{m}, c_{1}=c_{2}=$ $\ldots=c_{6}=2.94 M N-s / m$ (Schmitendorf et al., 1994). The dynamic parameters of the degree of freedom added to the structure in the isolated case are $m_{b}, c_{b}$ and $k_{b}$. The base mass $m_{b}$ is almost equal to the mass of the floors; the damping ratio is considered as $2 \%$; and the base stiffness $k_{b}$ is designed such that the fundamental period of the isolated structure is almost triple the fundamental period of the fixedbase structure (Villaverde, 2009). Therefore, the parameters of the base isolation model are taken as $m_{b}=345.6$ tons, $k_{b}=15.8 \mathrm{MN} / \mathrm{m}$ and $c_{b}=0.247 \mathrm{MN}-\mathrm{s} / \mathrm{m}$. The dynamic models of the fixed-base structure and the structure equipped with a semi-active base isolation system are shown in Figure 4.

An MR damper with a capacity of $1000(k N)$ and a maximum voltage of $10(v)$ was installed between the ground and base isolation system. The dynamic parameters of this damper are presented in Table 1 (Jung el al., 2003).

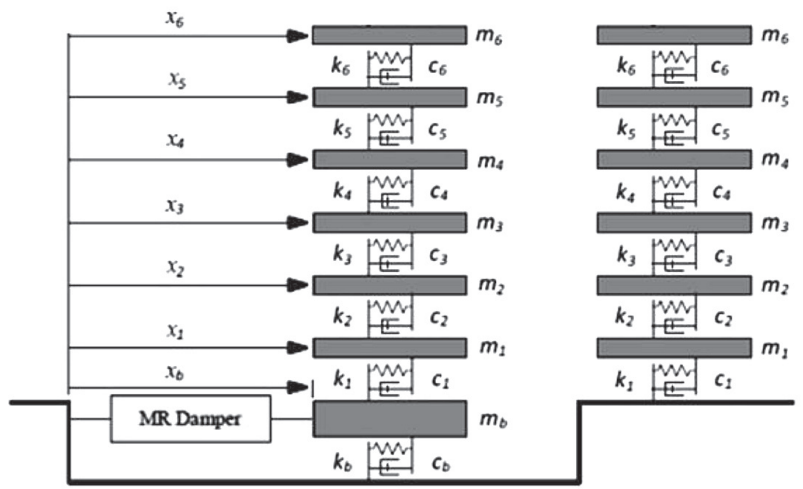

Fig. 4 Dynamic models of a structure uncontrolled and controlled by semi-active base isolation 
Tab. 1 Parameters of the modified Bouc-Wen model of the MR damper

\begin{tabular}{|c|c|c|c|}
\hline Parameter & Value & Parameter & Value \\
\hline$c_{0 a}$ & $110 \mathrm{kN.sec} / \mathrm{m}$ & $a_{a}$ & $46.2 \mathrm{kN} / \mathrm{m}$ \\
\hline$c_{0 b}$ & $114.3 \mathrm{kN.sec} / \mathrm{m} . V$ & $a_{b}$ & $41.2 \mathrm{kN} / \mathrm{m} . \mathrm{V}$ \\
\hline$k_{0}$ & $0.002 \mathrm{kN} / \mathrm{m}$ & $\gamma$ & $164 \mathrm{~m}^{-2}$ \\
\hline$c_{1 a}$ & $8359.2 \mathrm{kN.sec} / \mathrm{m}$ & $\beta$ & $164 \mathrm{~m}^{-2}$ \\
\hline$c_{1 b}$ & $7482.9 \mathrm{kN.sec} / \mathrm{m} . V$ & $\mathrm{~A}$ & 1107.2 \\
\hline$k_{1}$ & $0.0097 \mathrm{kN} / \mathrm{m}$ & $\mathrm{n}$ & 2 \\
\hline$x_{0}$ & 0 & $\eta$ & $100 \mathrm{sec}^{-1}$ \\
\hline
\end{tabular}

For the numerical simulation, a program has been made using MATLAB software; a comparison of the results of this program and the experimental study conducted by Dyke et al. (1996) is presented in Table 2. This comparison shows an acceptable level of accuracy of the program in modeling the MR damper's behavior.

Tab. 2 Verifying the results of the program with the experimental study

\begin{tabular}{|c|c|c|c|c|}
\hline \multirow{2}{*}{$\begin{array}{l}\text { Control } \\
\text { Strategy }\end{array}$} & \multicolumn{2}{|c|}{ Uncontrolled Structure } & \multicolumn{2}{|c|}{ Clipped-Optimal Control } \\
\hline & $\begin{array}{c}\text { Dyke et al. } \\
\text { (1996) }\end{array}$ & $\begin{array}{c}\text { Present } \\
\text { Research }\end{array}$ & $\begin{array}{c}\text { Dyke et al. } \\
\text { (1996) }\end{array}$ & $\begin{array}{c}\text { Present } \\
\text { Research }\end{array}$ \\
\hline$x_{1}$ & 0.538 & 0.542 & 0.114 & 0.113 \\
\hline$x_{2}$ & 0.820 & 0.836 & 0.185 & 0.190 \\
\hline $\begin{array}{c}x_{3} \\
(\mathrm{~cm})\end{array}$ & 0.962 & 0.973 & 0.212 & 0.215 \\
\hline & 856 & 848 & 696 & 688 \\
\hline$a_{2}$ & 1030 & 1032 & 739 & 698 \\
\hline $\begin{array}{c}a_{3} \\
\left(\mathrm{~cm} / \mathrm{s}^{2}\right)\end{array}$ & 1400 & 1413 & 703 & 682 \\
\hline$f(N)$ & & & 941 & 923 \\
\hline
\end{tabular}

The numerical analysis conducted in this paper can be classified into the following sections:

Section (a): performance of the passive hybrid base isolation system

Section (b): optimal response-related weighting matrix to control a semi-active base isolation system

Section (c): evaluation of the optimal response-related weighting matrix under the testing of earthquake records

\subsection{Performance of the passive hybrid base isolation system}

In this section, the performance of the hybrid base isolation system is evaluated when the MR damper is operating the same as passive control systems and its voltage is constant. The peak responses of the fixed-base structure (F-B), and the controlled structure by the single base isolation system (S-B-I), and the passive hybrid base isolation system with voltages of $0 v$ (P-Off) and $10 v$ (P-On) are reported in Table 3.

As shown in Table 3, using a single base isolation system without an MR damper can reduce the average of the peak accelerations and inter-story drifts by about 71 and $63 \%$, while the average of the peak base drift is excessive and should be controlled. To mitigate the peak base drift, using an MR damper with constant voltage is an effective method. In this case study, about a $76 \%$ reduction in the average of the peak base drifts has been achieved when the MR damper was employed with a constant voltage of $10 v$. Therefore, the passive hybrid base isolation system is an effective control system to control structures, but because this system cannot be adapted to different conditions, using its semi-active form, which has a capability to adapt under different conditions, is preferred.

\subsection{Optimal response-related weighting matrix to control a semi-active base isolation system}

In this section, different combinations of acceleration, displacement and velocity-related weighting matrices are considered as the response weighting matrix to determine the optimal response-related weighting matrix to control the semi-active base isolation system as presented in Table 4. Because the MR damper is added to the base isolation system to mitigate the peak base drift, the objective has been defined as the minimization of the peak base drift in determining the optimal response-related weighting matrix. The performance of the semi-active base isolation system has been evaluated for different values of the force-related weighting parameter whose peak base drift has been shown in Figure 5. For each combination, the optimal value of the force-related weighting parameter should be determined. As shown in Figure 5, lower values of the force-related weighting parameter can be considered as optimal values for all the combinations as well as for all four earthquakes. Therefore, $10^{-17}$ is selected as the optimal force-related weighting parameter. The peak responses of the structure have been presented in Figures 6 to 8 for this force-related weighting parameter and for the considered combinations of the response-related weighting matrix. As shown in Figure 6, the greatest reductions in the average of the peak base drift are achieved for the velocity $(\mathrm{V})$ and displacement-velocity (D-V) related weighting matrices, which are respectively about $74.3 \%$ and $75.2 \%$. Using these related weighting matrices can also reduce the peak responses of a superstructure effectively. For example, when the response weighting matrix is related to the velocity, about 67.9 and $80.8 \%$ reductions respectively in the average of the peak accelerations and inter-story drifts have been achieved as shown in Figures 7 and 8. Hence, it can be concluded that the velocity and displacement/velocity-related weighting matrices are the optimal response weighting matrices to control the semi-active base isolation. The time history of the MR damper voltage, the maximum response of the structure, and the MR damper force for the $\mathrm{D}-\mathrm{V}$ and acceleration-displacement-velocity $(\mathrm{A}-\mathrm{D}-\mathrm{V})$ related weighting matrices during the El Centro earthquake are shown in Figures 9 to 11.

Tab. 3 Peak response of structures under different earthquakes

\begin{tabular}{|c|c|c|c|c|c|c|c|c|c|c|c|}
\hline \multirow{2}{*}{ Earthquake } & \multicolumn{4}{|c|}{ Peak Acceleration $\left(\mathrm{cm} / \mathrm{s}^{2}\right)$} & \multicolumn{4}{|c|}{ Peak Inter-Story Drift $(\mathrm{cm})$} & \multicolumn{3}{|c|}{ Peak Base Drift $(\mathrm{cm})$} \\
\hline & F-B & S-B-I & P-Off & P-On & F-B & S-B-I & P-Off & P-On & S-B-I & P-Off & P-On \\
\hline El Centro (PGA=0.348g, 1940) & 890 & 256 & 205 & 225 & 3.76 & 1.21 & 1.07 & 0.54 & 29.61 & 25.39 & 6.48 \\
\hline Loma Prieta $(\mathrm{PGA}=0.278 \mathrm{~g}, 1989)$ & 812 & 119 & 112 & 210 & 3.28 & 0.59 & 0.54 & 0.61 & 14.36 & 12.36 & 8.04 \\
\hline Northridge (PGA $=0.535 \mathrm{~g}, 1994)$ & 416 & 177 & 146 & 259 & 1.78 & 1.02 & 0.83 & 0.42 & 25.10 & 19.87 & 4.09 \\
\hline Petrolia (PGA=0.163g, 1992) & 296 & 144 & 106 & 161 & 0.99 & 0.82 & 0.56 & 0.35 & 20.15 & 13.17 & 2.55 \\
\hline Average & 604 & 174 & 142 & 214 & 2.45 & 0.91 & 0.75 & 0.48 & 22.31 & 17.70 & 5.29 \\
\hline
\end{tabular}


Tab. 4 Various combinations of response-related weighting matrices

\begin{tabular}{|c|c|c|c|c|c|}
\hline Various sets & $q_{a}$ & $q_{d}$ & $q_{v}$ & Related weighting matrix & Performance index \\
\hline $\mathrm{A}$ & 1 & 0 & 0 & Acceleration & $J=\lim _{\tau \rightarrow \infty} \frac{1}{\tau}\left[\int_{0}^{\tau}\left(\ddot{X}^{2}(t)+r f_{c}^{2}\right) d t\right]$ \\
\hline $\mathrm{D}$ & 0 & 1 & 0 & Displacement & $J=\lim _{\tau \rightarrow \infty} \frac{1}{\tau}\left[\int_{0}^{\tau}\left(X^{2}(t)+r f_{c}^{2}\right) d t\right]$ \\
\hline $\mathrm{V}$ & 0 & 0 & 1 & Velocity & $J=\lim _{\tau \rightarrow \infty} \frac{1}{\tau}\left[\int_{0}^{\tau}\left(\dot{X}^{2}(t)+r f_{c}^{2}\right) d t\right]$ \\
\hline A-D & 1 & 1 & 0 & Acceleration-Displacement & $J=\lim _{\tau \rightarrow \infty} \frac{1}{\tau}\left[\int_{0}^{\tau}\left(\ddot{X}^{2}(t)+X^{2}(t)+r f_{c}^{2}\right) d t\right]$ \\
\hline A-V & 1 & 0 & 1 & Acceleration-Velocity & $J=\lim _{\tau \rightarrow \infty} \frac{1}{\tau}\left[\int_{0}^{\tau}\left(\ddot{X}^{2}(t)+\dot{X}^{2}(t)+r f_{c}^{2}\right) d t\right]$ \\
\hline D-V & 0 & 1 & 1 & Displacement-Velocity & $J=\lim _{\tau \rightarrow \infty} \frac{1}{\tau}\left[\int_{0}^{\tau}\left(X^{2}(t)+\dot{X}^{2}(t)+r f_{c}^{2}\right) d t\right]$ \\
\hline A-D-V & 1 & 1 & 1 & Full response & $J=\lim _{\tau \rightarrow \infty} \frac{1}{\tau}\left[\int_{0}^{\tau}\left(\ddot{X}^{2}(t)+X^{2}(t)+\dot{X}^{2}(t)+r f_{c}^{2}\right) d t\right]$ \\
\hline
\end{tabular}

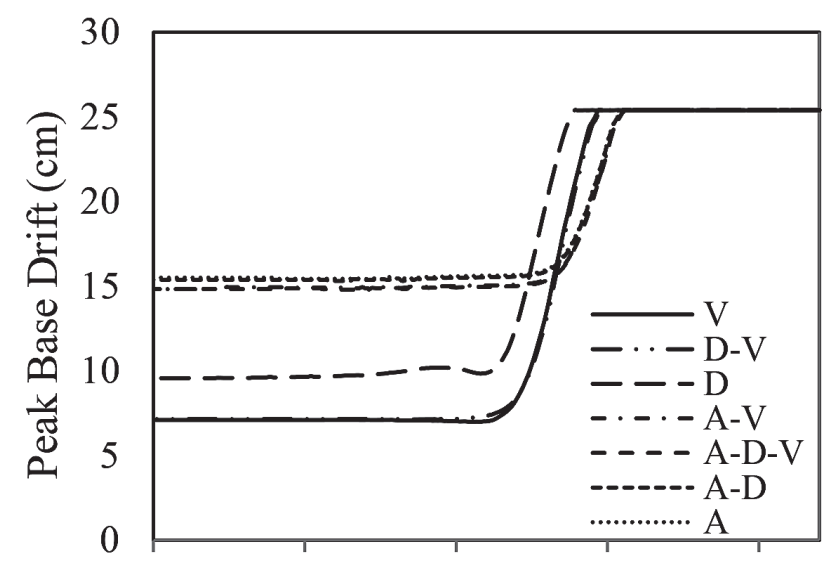

$1 \mathrm{E}-25 \quad 1 \mathrm{E}-20 \quad 1 \mathrm{E}-15 \quad 1 \mathrm{E}-10 \quad 0,00001$

Force Weighting Parameter

(a): El Centro

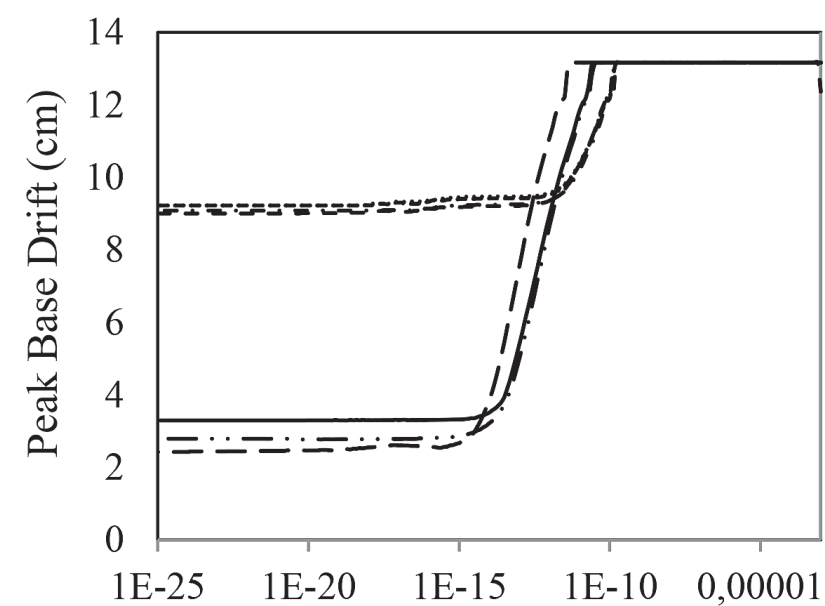

Force Weighting Parameter

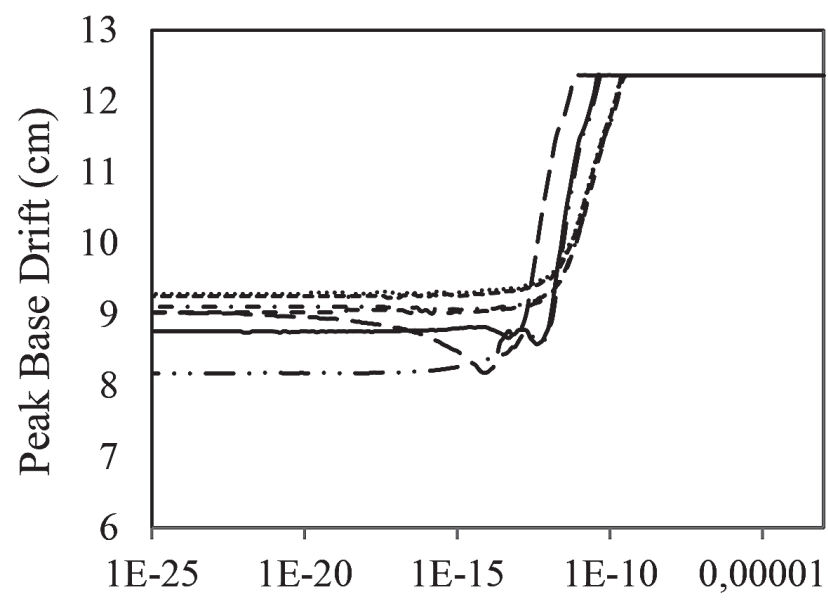

Force Weighting Parameter

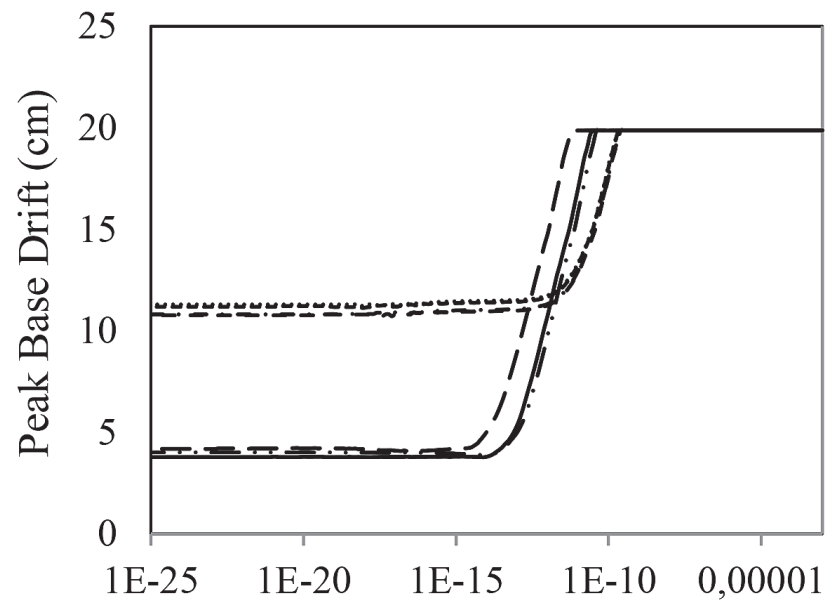

Force Weighting Parameter

(c): Petrolia

(d): Northridge

Fig. 5 Peak base drift for different sets of the response weighting matrix and various force weighting parameters 


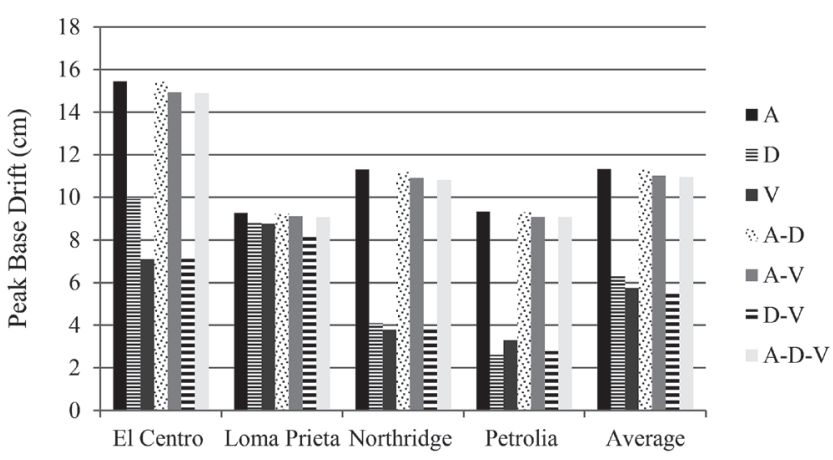

Fig. 6 Peak base drift for various sets of the response weighting matrix

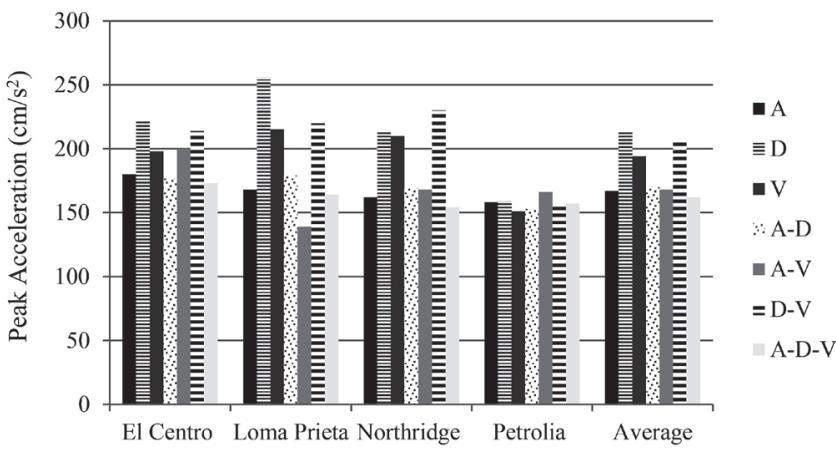

Fig. 7 Peak acceleration for various sets of the response weighting matrix

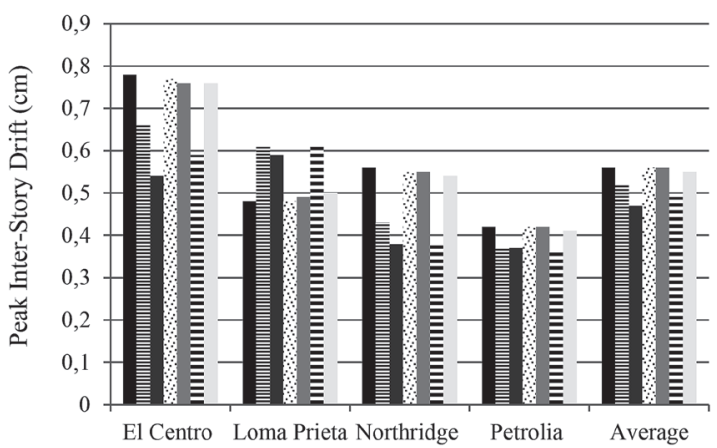

Fig. 8 Peak inter-story drift for various sets of the response weighting matrix

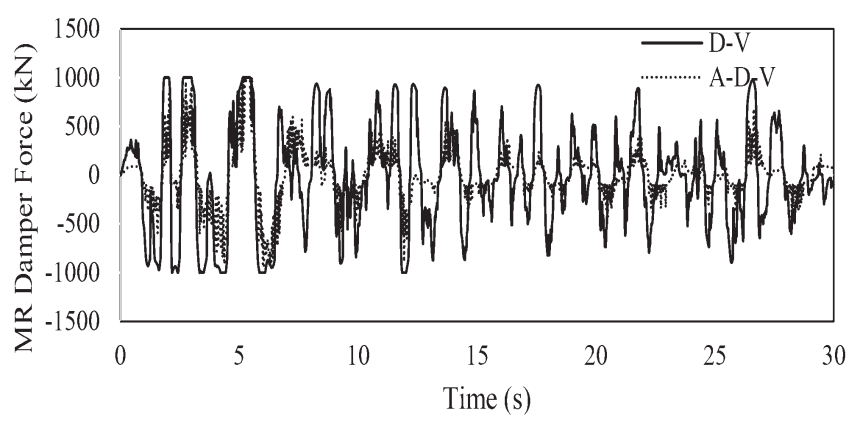

Fig. 11 MR damper force

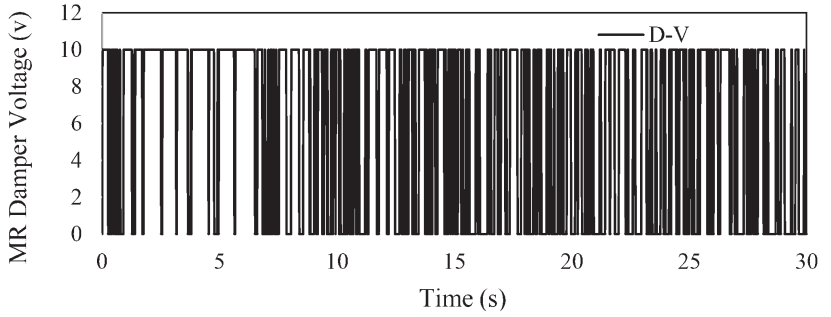

(a): Displacement-velocity related weighting matrix

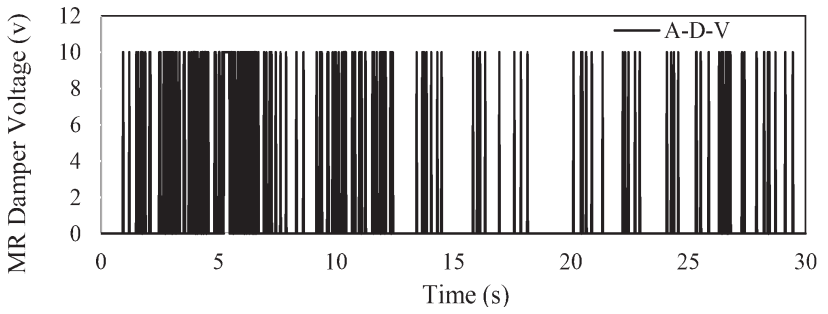

(b) : Acceleration-displacement-velocity related weighting matrix Fig. 9 MR damper voltage

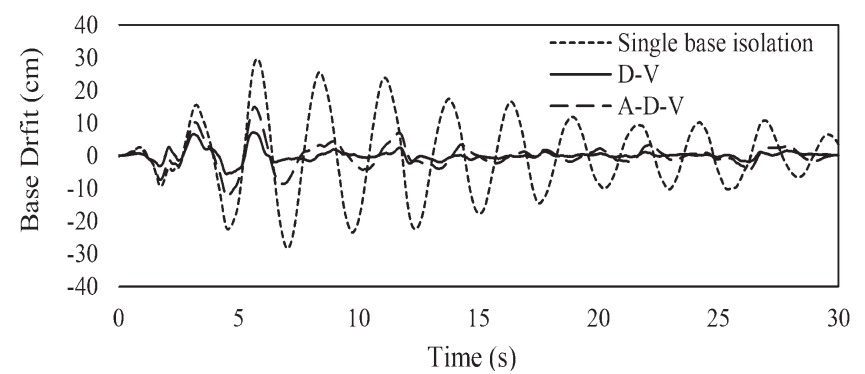

(a): Base drift

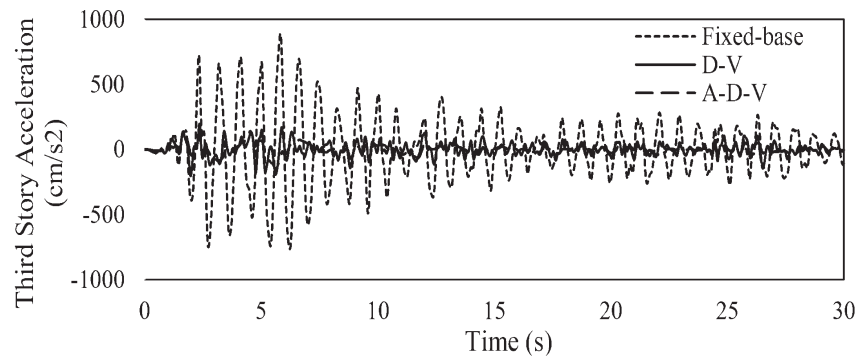

(b): First story drift

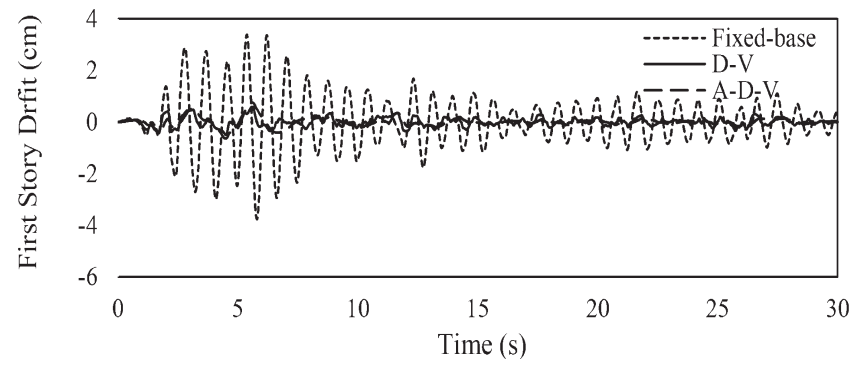

(c): Third story acceleration

Fig. 10 Comparison of (a) base drift, (b) first story drift, and (c) third story acceleration 
Tab. 5 Peak base drift (cm) for various sets of the response weighting parameters

\begin{tabular}{|l|c|c|c|c|c|c|c|c|}
\hline \multirow{2}{*}{ Earthquake } & \multirow{2}{*}{ Single base isolation } & \multicolumn{5}{|c|}{ Semi-active hybrid base isolation } \\
\cline { 3 - 8 } & & A & D & V & A-D & A-V & D-V & A-D-V \\
\hline Olympia (PGA=0.28g, 1949) & 20.32 & 9.90 & 2.86 & 2.86 & 9.85 & 9.48 & 2.71 & 9.45 \\
\hline Parkfield California (PGA=0.35g, 1966) & 7.76 & 3.53 & 1.47 & 1.50 & 3.53 & 3.39 & 1.48 & 3.37 \\
\hline San Helena Montana (PGA=0.146g, 1935) & 5.16 & 3.73 & 2.96 & 2.31 & 3.71 & 3.70 & 2.29 & 3.70 \\
\hline Taft (PGA=0.156, 1952) & 10.93 & 4.11 & 3.47 & 2.66 & 4.11 & 4.04 & 2.91 & 4.01 \\
\hline Northridge (PGA=0.344g, 1994) & 15.44 & 10.22 & 9.16 & 8.54 & 10.21 & 10.14 & 8.87 & 10.11 \\
\hline Average Reduction(\%) & 11.92 & 6.30 & 3.98 & 3.57 & 6.28 & 6.15 & 3.65 & 6.13 \\
& - & 47.2 & 66.6 & 70.0 & 47.3 & 48.4 & 69.4 & 48.6 \\
\hline
\end{tabular}

${ }^{*}$ Reduction percentages defined by $(\mathrm{S}-\mathrm{B}-\mathrm{I}-\mathrm{Semi}$-Active) $/ \mathrm{S}-\mathrm{B}-\mathrm{I} \times 100$

Tab. 6 Peak acceleration $\left(\mathrm{cm} / \mathrm{s}^{2}\right)$ for various sets of the response weighting parameters

\begin{tabular}{|l|c|c|c|c|c|c|c|c|c|}
\hline \multirow{2}{*}{ Earthquake } & \multirow{2}{*}{ Fixed-base } & Single base isolation & \multicolumn{5}{|c|}{ Semi-active hybrid base isolation } \\
\cline { 5 - 11 } & & & A & D & V & A-D & A-V & D-V & A-D-V \\
\hline Olympia & 531 & 141 & 156 & 232 & 203 & 149 & 149 & 188 & 160 \\
\hline Parkfield California & 554 & 59 & 152 & 281 & 270 & 159 & 136 & 273 & 133 \\
\hline San Helena Montana & 310 & 44 & 84 & 154 & 136 & 114 & 139 & 150 & 97 \\
\hline Taft & 484 & 80 & 114 & 188 & 173 & 107 & 143 & 172 & 117 \\
\hline Northridge & 932 & 110 & 175 & 184 & 224 & 142 & 168 & 219 & 180 \\
\hline Average & 562 & 87 & 136 & 208 & 201 & 134 & 147 & 200 & 137 \\
Reduction(\%) & - & 84.6 & 75.8 & 63.0 & 64.2 & 76.1 & 73.9 & 64.4 & 75.6 \\
\hline
\end{tabular}

"Reduction percentages defined by (F-B - Semi-Active)/ F-B $\times 100$

Tab. 7 Peak inter-story drift (cm) for various sets of the response weighting parameters

\begin{tabular}{|l|c|c|c|c|c|c|c|c|c|}
\hline \multirow{2}{*}{ Earthquake } & \multirow{2}{*}{ Fixed-base } & \multirow{2}{*}{ Single base isolation } & \multicolumn{5}{|c|}{ Semi-active hybrid base isolation } \\
\cline { 5 - 10 } & & & $\mathrm{A}$ & $\mathrm{D}$ & $\mathrm{V}$ & $\mathrm{A}-\mathrm{D}$ & $\mathrm{A}-\mathrm{V}$ & $\mathrm{D}-\mathrm{V}$ & A-D-V \\
\hline Olympia & 1.86 & 0.82 & 0.47 & 0.41 & 0.43 & 0.47 & 0.45 & 0.45 & 0.45 \\
\hline Parkfield California & 1.38 & 0.32 & 0.19 & 0.55 & 0.52 & 0.19 & 0.19 & 0.53 & 0.19 \\
\hline San Helena Montana & 1.04 & 0.21 & 0.20 & 0.35 & 0.32 & 0.20 & 0.20 & 0.33 & 0.20 \\
\hline Taft & 1.76 & 0.45 & 0.24 & 0.37 & 0.34 & 0.24 & 0.24 & 0.35 & 0.24 \\
\hline Northridge & 3.91 & 0.63 & 0.58 & 0.57 & 0.57 & 0.59 & 0.59 & 0.57 & 0.59 \\
\hline $\begin{array}{l}\text { Average } \\
\text { Reduction(\%) }\end{array}$ & 1.99 & 0.49 & 0.34 & 0.45 & 0.44 & 0.34 & 0.33 & 0.45 & 0.33 \\
\hline
\end{tabular}

*Reduction percentages defined by (F-B - Semi-Active)/ F-B $\times 100$

\subsection{Evaluation of the optimal response-related weighting matrix under testing earthquake records}

In this section, the performance of the semi-active base isolation system is evaluated for different combinations of the response-related weighting matrices under testing earthquake records to investigate the optimal response weighting matrices of other earthquakes. The peak responses of the structure uncontrolled and controlled by the semi-active base isolation system have been shown in Tables 5 to 7 . According to the results of Table 5, the greatest reduction in the average of the peak base drifts under testing earthquake records has been obtained for the velocity and displacement/velocity-related weighting matrices. The peak acceleration and inert-story drift can also be miti- gated by using these matrices as shown in Tables 6 and 7. Therefore, the velocity and displacement-velocity related weighting matrices are optimal response-related weighting matrices to control the behavior of the semi-active base isolation system under both the design and testing of the earthquake records.

\section{CONCLUSIONS}

This research has studied the performance of a semi-active hybrid base isolation composed of a base isolation system and an MR damper for different combinations of displacement, velocity and acceleration-related weighting matrices to investigate the optimal set for minimizing the maximum base drift. To achieve this end, seven $\mathrm{H}_{2} / \mathrm{LQG}$ 
control algorithms have been designed; which various combinations of the structural responses have been weighted in each of the designed algorithms. Also, the optimal value of the force-related weighting parameter has been determined for each set of the response-related weighting matrices. In addition to the use of a semi-active MR damper, this damper has been employed in a passive form with constant voltage. For the numerical simulation, a six-story shear frame has been considered, and for each combination of the response-related weighting matrices, the performance of the control system has been assessed for different values of the force-related weighting parameter. The results show that the optimal value of the force-related weighting parameter is almost independent of the response-related weighting matrices as well as the earthquake records and that an optimal value can be selected for different cases. Comparing various sets of the re- sponse-related weighting matrices shows that the optimal sets are the velocity and displacement/velocity-related weighting matrices; this conclusion has also been verified when testing earthquake records. For example, using a displacement/velocity-related weighting matrix to control the behavior of a semi-active base isolation system can reduce the average of the peak base drifts, inter-story drifts, and accelerations under design records by about $75.2,80$ and $66.1 \%$ respectively. The results of the passive hybrid base isolation system show that when the design objective is defined, the minimization of the maximum base drift, can also be used by using the passive form with the maximum voltage, but using the semi-active form has a higher priority than the passive form because of the adaptation capability of the semi-active MR damper under different conditions. 


\section{REFERENCES}

Ali, S.F. - Ramaswamy, A. (2009) Hybrid structural control using magnetorheological dampers for base isolated structures. Smart Materials and Structures, Vol. 18, No. 5, 055011.

Bahar, O. - Banan, M.R. - Mahzoon, M. - Kitagawa, Y. (2003) Instantaneous optimal Wilson- $\theta$ control method. Journal of Engineering Mechanics, Vol. 129, No. 11, pp. 1268-1276.

Bharti, S.D. - Dumne, S.M. - Shrimali, M.K. (2014) Earthquake response of asymmetric building with $M R$ damper. Earthquake Engineering and Engineering Vibration, Vol. 13, No. 2, pp. 305316.

Cho, S.W. - Jung, H.J. - Lee, I.W. (2005) Smart passive system based on magnetorheological damper. Smart Materials and Structures, Vol. 14, No. 4, pp. 707-714.

Constantinou, M.C. - Symans, M.D. - Tsopelas, P. - Taylor, D.P. (1999) Fluid dampers for application of seismic energy dissipation and seismic isolation. Proc., ATC-17-1 Seminar on Seismic Isolation, Passive Energy Dissipation and Active Control, pp. 581-591.

Dyke, S.J. - Spencer, B.F. - Sain, M.K. - Carlson, J.D. (1996) Modeling and control of magnetorheological dampers for seismic response reduction. Smart Materials and Structures, Vol. 5, No. 5, pp. 565-575.

Fan, Y.C. - Loh, C.H. - Yang, J.N - Lin, P.Y. (2009) Experimental performance evaluation of an equipment isolation using $M R$ dampers. Earthquake Engineering and Structural Dynamics, Vol. 38, No. 3, pp. 285-305.

Inaudi, J.A. - Kelly, J.M. (1993) Hybrid isolation systems for equipment protection. Earthquake Engineering and Structural Dynamics, Vol. 22, No. 4, pp. 297-313.

Jing, C. - Youlin, X. - Weilian, Q. - Zhilun, W. (2004) Seismic response control of a complex structure using multiple MR dampers: experimental investigation. Earthquake Engineering and Engineering Vibration, Vol. 3, No. 2, pp. 181-193.

Johnson, E.A. - Ramallo, J.C. - Spencer, B.F. - Sain, M.K. (1999) Intelligent base isolation systems. Proc., Second World Conf. on Structural Control, Kyoto, Japan, Vol. 1, pp. 367-376.

Jung, H.J. - Choi, K.M. - Spencer, B.F. - Lee, I.W. (2006) Application of some semi-active control algorithms to a smart base-isolated building employing MR dampers. Structural Control and Health Monitoring, Vol. 13, No. 2-3, pp. 693-704.

Jung, H.J. - Spencer, B.F. - Lee, I.W. (2003) Control of seismically excited cable-stayed bridge employing magnetorheological fluid dampers. Journal of Structural Engineering, Vol. 129, No. 7, pp. 873-883.

Lee, H.J. - Yang, G. - Hung, H.J. - Spencer, B.F. - Lee, I.W. (2006) Semi-active neurocontrol of a base-isolated benchmark structure. Structural Control and Health Monitoring, Vol. 13, No. 2, pp. 682-692.
Madden, G.J. - Symans, M.D. - Wongprasert, N. (2002) Experimental verification of seismic response of building frame with adaptive sliding base-isolation system. Journal of Structural Engineering, Vol. 128, No. 8, pp. 1037-1045.

Mohebbi, M - Dadkhah, H. - Shakeri, K. (2015) Optimal hybrid base isolation and MR damper. International Journal of Optimization in Civil Engineering, Vol. 5, No. 4, pp. 493-509.

Nagarajaiah, S. - Riley, M.A. - Reinhorn, A. (1993) Control of sliding-isolated bridge with absolute acceleration feedback. Journal of Engineering Mechanics, Vol. 119, No. 11, pp. 2317-2332.

Narasimhan, S. - Nagarajaiah, S. (2006) Smart base isolated buildings with variable friction systems: Ho controller and SAIVF device. Earthquake Engineering and Structural Dynamics, Vol. 35, No. 8, pp. 921-942.

Ramallo, J.C. - Johnson, E.A. - Spencer, B.F. (2002) Smart base isolation systems. Journal of Engineering Mechanics, Vol. 128, No. 10, pp. 1088-99.

Sahasrabudhe, S.S. - Nagarajaiah, S. (2005) Semi-active control of sliding isolated bridges using MR dampers: an experimental and numerical study. Earthquake Engineering and Structural Dynamics, Vol. 34, No. 8, pp. 965-983.

Schmitendorf, W.E. - Jabbari, F. - Yang, J.N. (1994) Robust control techniques for buildings under earthquake excitation. Earthquake Engineering and Structural Dynamics, Vol. 23, No. 5, pp. 539-552.

Shook, D. - Lin, P.Y. - Lin, T.K. - Roschke, P.N. (2007) A comparative study in the semi-active control of isolated structures. Smart Materials and Structures, Vol. 16, No. 4, pp. 1433-1446.

Spencer, B.F. - Dyke, S.J. - Sain, M.K. - Carlson, J.D. (1997) Phenomenological model for magnetorheological dampers. Journal of Engineering Mechanics, Vol. 123, No. 3, pp. 230-238.

Villaverde, R. (2009) Fundamental concepts of earthquake engineering. Taylor and Francis group, USA.

Wongprasert, N. - Symans, M.D. (2005) Experimental evaluation of adaptive elastomeric base-isolated structures using variable-orifice fluid dampers. Journal of Structural Engineering, Vol. 131, No. 6, pp. 867-877.

Yang, J.N. - Wu, J.C. - Reinhorn, A.M. - Riley, M. (1996) Control of sliding-isolated buildings using sliding-mode control. Journal of Structural Engineering, Vol. 122, No. 2, pp. 179-186.

Yoshioka, H. - Ramallo, J.C. - Spencer, B.F. (2002) Smart base isolation strategies employing magnetorheological dampers. Journal of Engineering Mechanics, Vol. 128, No. 5, pp. 540-551. 